\title{
Is there any change in surgeon's attitude to the management of ankle fractures accompanying syndesmotic injury? A nationwide survey
}

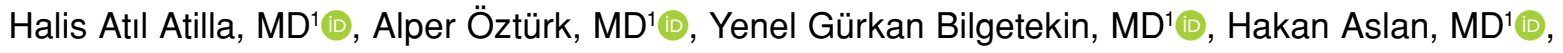 \\ Mehmet Orçun Akkurt, MD²(D), Mutlu Akdoğan, MD ${ }^{1}$ \\ ${ }^{1}$ Department of Orthopedics and Traumatology, Dışkapı Yıldırım Beyazıt Training and Research Hospital, Ankara, Turkey \\ ${ }^{2}$ Department of Orthopedics and Traumatology, Ankara City Hospital, Ankara, Turkey
}

Ankle fractures accompanied by syndesmotic injury are common traumas in orthopedic practice. The mechanism of these injuries has been clearly described. ${ }^{[1]}$ There is a consensus that diastasis in syndesmosis should be reduced and, if not, it may result in severe ankle arthrosis. ${ }^{[2]}$ However, there is no consensus on the management of ankle fractures accompanying syndesmotic injury. ${ }^{[3-6]}$ Although syndesmotic screw fixation after reduction is widely accepted as the gold standard treatment, a consensus has not yet been reached in the literature about the details of the screw fixation. ${ }^{[3]}$ There is also disagreement about rehabilitation after treatment. ${ }^{[7]}$ Various studies continue to search for solutions to these controversial issues; however, surgeons prefer to use the methods which they are familiar with because of the lack of evidence. ${ }^{[8,9]}$

Received: April 17, 2020

Accepted: June 20, 2020

Published online: August 27, 2020

Correspondence: Halis Atıl Atilla, MD. Dışkapı Yıldırım Beyazı† Eğitim ve Araştırma Hastanesi Ortopedi ve Travmatoloji Kliniği 06110 Dışkapı, Ankara, Türkiye.

E-mail: dratilatilla@hotmail.com

Doi: $10.5606 /$ ehc. 2020.75527

Citation: Atilla HA, Öztürk A, Bilgetekin YG, Aslan H, Akkurt MO, Akdoğan $M$. Is there any change in surgeon's attitude to the management of ankle fractures accompanying syndesmotic injury? A nationwide survey. Jt Dis Relat Surg 2020;31(3):548-556.

(2020 All right reserved by the Turkish Joint Diseases Foundation

This is an open access article under the terms of the Creative Commons Attribution-NonCommercial License, which permits use, distribution and reproduction in any medium, provided the original work is properly cited and is not used for commercial purposes (http://creativecommons.org/licenses/by-nc/4.0/).

\section{ABSTRACT}

Objectives: This study aims to investigate the attitudes of orthopedic surgeons to the management of ankle fractures accompanied by syndesmotic injury with a nationwide survey.

Patients and methods: In the first step of this descriptive study, an electronic survey was prepared in Google drive and a survey link was sent to the Turk-Ortopedi e-mail group between 09 and 19 January 2019. The orthopedic surgeons and residents were requested to complete the questionnaire. A total of 320 orthopedic surgeons (77\%) and residents (23\%) participated in the survey. The responses were analyzed statistically. To evaluate the changing attitudes, our results were compared with the surgeon survey studies key worded "syndesmotic injury" in PubMed.

Results: The majority of the participants stated that they used the hook test, external rotation stress test, and fluoroscopy together $(47.2 \%)$ for the diagnosis of syndesmotic injury during the operation. Of the participants, the majority (93\%) reported to use metallic syndesmotic screws, and 59\% reported to remove the syndesmotic screw routinely. Young surgeons with five to 10 years of experience preferred intraoperative diagnosis methods compared to surgeons with more than 20 years of experience. Foot and ankle surgeons and sports surgeons reported to allow weight bearing before removal of the screw much more than other unspecified branches.

Conclusion: The preferences of the surgeon vary in syndesmotic injuries and there is still no consensus regarding diagnosis and rehabilitation. Compared to the past decade, fewer surgeons prefer to remove the screws today.

Keywords: Ankle fracture, surgeon preference, survey, syndesmotic injury.

Although there were several survey studies all over the world, there is no study determining the trends and attitudes of Turkish Orthopedic surgeons to the management of this particular type of injury. Besides, there is no comparison of surveys in the last decade determining current surgeon attitudes according to 
changing evidence. Therefore, in this study, we aimed to investigate the attitudes of orthopedic surgeons to the management of ankle fractures accompanied by syndesmotic injury with a nationwide survey.

\section{PATIENTS AND METHODS}

This descriptive study was conducted at the Dışkapı Training and Research Hospital. Controversial issues regarding the treatment of ankle fractures accompanied by syndesmotic injury were determined by reviewing recent meta-analyses and reviews on this topic. ${ }^{[3-5]}$ We performed a comprehensive PubMed search regarding surgeon surveys with the keywords "syndesmotic injury". Controversial issues were compared with these surveys from other countries. ${ }^{[8-17]}$ The debatable topics on the diagnosis, treatment, and follow-up of ankle fractures accompanied by a syndesmotic injury were determined and a questionnaire was prepared. The survey consisted of 16 questions in four sections: surgeon characteristics (4 questions), syndesmotic injury diagnosis strategy (2 questions), treatment strategy (7 questions), and postoperative follow-up (3 questions) (Table I). The study protocol was approved by the Dışkapı Training and Research Hospital Institutional Review Board (07.01.201958/12). The study was conducted in accordance with the principles of the Declaration of Helsinki.

The questionnaire was checked by three orthopedic surgeons with at least 10 years of orthopedic surgery experience and three orthopedic residents to test the content of the questionnaire and the use of common terminology and ease of application in various experience groups.

The final survey was prepared in a multiplechoice form in the Google drive. The survey was sent three times between 09 and 19 January 2019 to the Turk-Ortopedi e-mail group which is an electronic mail group to which the majority of Turkish orthopedic surgeons are subscribed. The orthopedic surgeons and residents were informed and requested to complete the questionnaire. There were approximately 5,000 orthopedic surgeons and residents serving in Turkey at the time of survey completion. The ideal sample size was found to be between 253 to 357 correspondents with a 95\% confidence interval and a 5-6\% margin of error. Data collection was stopped after the achievement of 323 correspondents. Thus a total of 323 orthopedic surgeons and residents participated in the survey. Three improperly completed questionnaires were excluded and finally 320 were included.

\section{Statistical analysis}

Statistical analysis of the data obtained from the survey was performed using the IBM SPSS for Windows version 20.0 software (IBM Corp., Armonk, NY, USA). Descriptive statistics for categorical variables were presented as numbers and percentages. In the group comparisons, chi-square test statistics were used when the chi-square condition was satisfied, and Fisher's exact test was used when the condition was not provided. To determine from which group the difference originated for significant tests, the percentages of columns in the groups were compared and significant differences were determined with Bonferroni correction. A value of $p<0.05$ was considered statistically significant.

\section{RESULTS}

Of the 320 records, $75(23.4 \%)$ were from residents and $245(76.6 \%)$ from surgeons. The majority of all participants $(60.7 \%)$ contributed from an academic institution such as university or training and research hospital. Surgical experience was recorded as five to 10 years by $26.9 \%$, and $>10$ years by $50 \%$. Most of the residents (73.3\%) participating in the study consisted of senior residents (Table I).

The majority of the participants stated that they used the hook test, external rotation stress test, and fluoroscopy together $(47.2 \%)$ for the diagnosis of syndesmotic injury during the operation. Details regarding diagnosis are given in Table I.

Most of the surgeons (92.8\%) who decided to use syndesmotic fixation stated that they used metallic syndesmotic screws, and $5.6 \%$ used suture fixation device (SFD) (Table I). None of the foot and ankle surgeons used SFD. Four percent of the general orthopedic surgeons, $9.6 \%$ of sports surgeons, and $8.8 \%$ of trauma surgeons stated that they used SFD instead of a syndesmotic screw.

The majority of the respondents (57.9\%) stated that they allowed weight bearing without removing the syndesmotic screw, and $58.8 \%$ stated that they routinely removed the syndesmotic screw. Of the surgeons who removed the screws, the majority (56.8\%) stated that they removed the screws in the first eight weeks, while $31.9 \%$ stated that they waited 12 weeks or more. Results regarding postoperative management are given in Tables I and II.

The results of the analysis showed that young surgeons with 5 to 10 years of experience significantly preferred intraoperative diagnosis methods compared to surgeons with more than 20 years of experience 


\begin{tabular}{|c|c|c|c|c|c|}
\hline \multicolumn{6}{|c|}{$\begin{array}{l}\text { TABLE I } \\
\text { asponses of survey }(n=320)\end{array}$} \\
\hline & $\mathrm{n}$ & $\%$ & & $\mathrm{n}$ & $\%$ \\
\hline \multicolumn{3}{|l|}{ Institution } & \multicolumn{3}{|l|}{ Number of cortices fixed with syndesmosis screw } \\
\hline Private Hospital & 55 & 17.2 & 3 Cortices & 212 & 67.3 \\
\hline State Hospital & 63 & 19.7 & 4 Cortices & 102 & 32.4 \\
\hline Training and Research Hospital & 125 & 39.1 & Other & 1 & 0.3 \\
\hline University Hospital & 69 & 21.6 & & & \\
\hline Private Practice & 8 & 2.5 & & & \\
\hline \multicolumn{3}{|l|}{ Title } & Method of syndesmosis reduction in surgery & & \\
\hline Faculty member & 80 & 25 & Squeezing with hand & 148 & 46.3 \\
\hline Surgeon & 165 & 51.6 & Squeezing with clamp & 139 & 43.4 \\
\hline Resident & 75 & 23.4 & Other & 33 & 10.3 \\
\hline \multirow{2}{*}{\multicolumn{3}{|c|}{$\begin{array}{l}\text { Experience in orthopedics } \\
\text { (including residency period), (year) }\end{array}$}} & Ankle position when placing syndesmosis screw & & \\
\hline & & & Maximum dorsiflexion & 110 & 34.4 \\
\hline $0-2$ & 19 & 5.9 & Neutral & 121 & 37.8 \\
\hline $2-5$ & 55 & 17.2 & Zero degree dorsiflexion & 82 & 25.6 \\
\hline $5-10$ & 86 & 26.9 & Other & 7 & 2.2 \\
\hline $10-15$ & 61 & 19.1 & & & \\
\hline $15-20$ & 40 & 12.5 & & & \\
\hline Over 20 & 59 & 18.4 & & & \\
\hline \multicolumn{3}{|l|}{ Special interest (subspecialty) } & Level of syndesmosis screw & & \\
\hline General orthopedics & 100 & 31.3 & (distance from joint level) & & \\
\hline Foot and ankle surgery & 13 & 4.1 & $0-2 \mathrm{~cm}$ & 46 & 14.4 \\
\hline Trauma & 102 & 31.9 & $2-4 \mathrm{~cm}$ & 248 & 77.5 \\
\hline Sports & 62 & 19.4 & Above $4 \mathrm{~cm}$ (supra syndesmotic level) & 20 & 6.3 \\
\hline Other & 43 & 13.4 & From the empty hole on the plate & 6 & 1.9 \\
\hline \multicolumn{3}{|l|}{ Diagnosis method of syndesmotic injury } & Routine repair of deltoid ligament in patients with & & \\
\hline Plain radiographies & 110 & 34.4 & diastasis & & \\
\hline Stress radiographies & 102 & 31.9 & No & 233 & 72.8 \\
\hline Intraoperative methods & 90 & 28.1 & Yes & 87 & 27.2 \\
\hline Other & 18 & 5.6 & & & \\
\hline \multicolumn{3}{|l|}{ Confirmation method of syndesmotic injury } & $\begin{array}{l}\text { Allowing weight bearing without removing the } \\
\text { syndesmosis screw }\end{array}$ & & \\
\hline Hook test & 43 & 13.4 & No & 184 & 57.9 \\
\hline Fluoroscopy with external rotation stress & 151 & 47.2 & Yes & 134 & 42.1 \\
\hline Both methods & 50 & 15.6 & & & \\
\hline $\begin{array}{l}\text { I decide before surgery } \\
\text { Other }\end{array}$ & 6 & 1.9 & & & \\
\hline \multicolumn{3}{|l|}{ Syndesmotic fixation method preference used in } & Routine removal of the syndesmosis screw & & \\
\hline ankle fracture & 296 & 92.8 & No & 187 & 58.8 \\
\hline Metallic syndesmotic screw & 21 & 5.6 & Yes & 131 & 41.2 \\
\hline Suture button & 2 & 0.6 & & & \\
\hline Bioabsorbable screw & & & & & \\
\hline \multicolumn{3}{|l|}{ Diameter preference while using screws } & Removal time of the syndesmosis screw & & \\
\hline $3.5 \mathrm{~mm}$ & 216 & 68.6 & (weeks after operation) & & \\
\hline $4.5 \mathrm{~mm}$ & 93 & 29.5 & $6^{\text {th }}$ week & 68 & 25.9 \\
\hline \multirow[t]{4}{*}{ Other } & 6 & 1.9 & $8^{\text {th }}$ week & 83 & 32.3 \\
\hline & & & $12^{\text {th }}$ week & 72 & 28.3 \\
\hline & & & Later & 10 & 3.9 \\
\hline & & & Other & 24 & 9.3 \\
\hline
\end{tabular}

$(\mathrm{p}<0.05)$. The least experienced residents stated that they often allowed weight bearing without screw removal and fixed the syndesmosis in neutral position $(\mathrm{p}<0.05)$. The statistically significant details regarding the experience are given in Table II.

Physicians interested in hand surgery, spine, arthroplasty and tumor were defined as other fields and participated in the survey at the rate of $13.4 \%$. Although syndesmotic injury is frequently encountered by every specialist in orthopedic surgery, it is more of a concern for general orthopedics, trauma surgery, sports surgery, and foot surgery. The rate of participants involved in these four branches was 86.7\% (Table I).

There was no significant difference found between the results except in respect of screw diameter and weight-bearing recommendation of subspecialists. The screw diameter preference of $3.5 \mathrm{~mm}$ was 


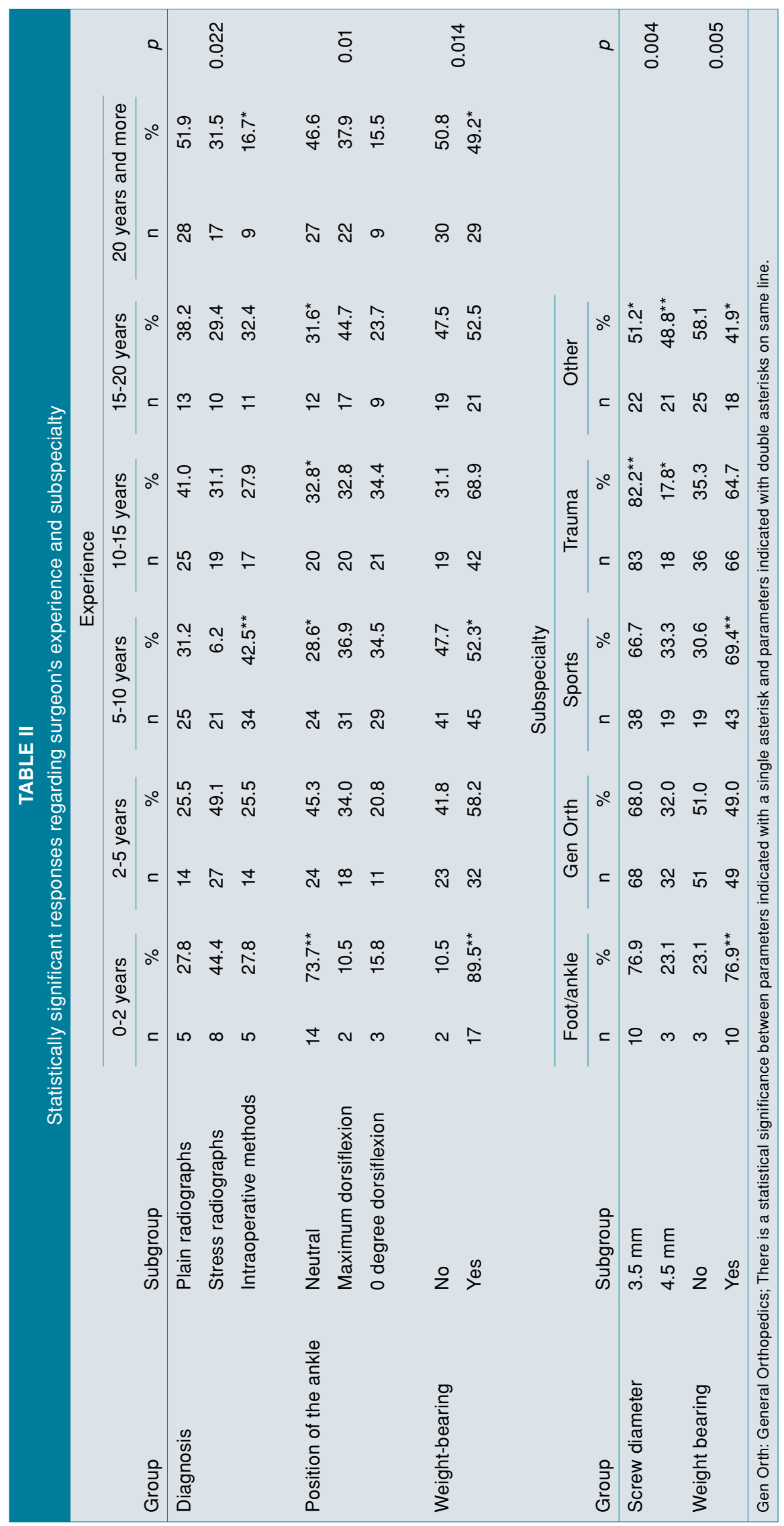


reported by $82.2 \%$ of trauma surgeons, which was higher than the responses of other subbranches $(p<0.05)$. The surgeons who used the $4.5 \mathrm{~mm}$ screw most were the surgeons in other unspecified areas. Foot and ankle surgeons and sports surgeons tended to allow weight bearing before removal of the screw much more than other unspecified branches $(\mathrm{p}<0.05)$ (Table II).

\section{DISCUSSION}

In this study, we found that there is no consensus on the majority of the questions regarding the diagnosis and follow-up of ankle fractures accompanied by syndesmotic injury. Regarding the treatment, there seems to be a consensus on three cortices fixation of $3.5 \mathrm{~mm}$, metallic screw from $2-4 \mathrm{~cm}$ distance from the joint without the repair of deltoid ligament. However, there was no consensus regarding syndesmosis reduction technique and ankle position during screw fixation. When compared with the literature, routine screw removal rate was the only changing attitude of surgeons during the last decade. ${ }^{[18]}$

The survey was delivered within an e-mail group which is the most widely used e-mail network (which had 2,180 members at the time of delivery) by orthopedic surgeons in Turkey. A total of 320 valid questionnaires were completed, with a participation rate of approximately $15 \%$. The average participation rate in studies investigating surgeon preferences for ankle injuries since 2008 is approximately $28 \%{ }^{[8-17]}$ More participants were reached than the average ${ }^{[8-17]}$ although the participation rate seems low. In addition, there was participation from a wide range of experience from residents to faculty members. This study is one of the few studies in the literature to include respondents from almost every working environment such as universities or teaching hospitals etc. The study principles of the current and previous studies are given in Table III.

There is no consensus on the preoperative diagnosis of syndesmotic injury. More than twothirds of the respondents stated that they performed imaging in addition to standard conventional radiographs. This rate was similar to those of UK and Netherland studies (Table IV). ${ }^{[8,9]}$ While conventional radiographs were used most frequently before 2010 in the diagnosis of syndesmotic injuries, the preference for the use of stress radiographs has increased since then. ${ }^{[11,16]}$ There is a rising demand for stress radiographs and less use of conventional radiographs in the current study (Table IV). ${ }^{[8-12,16]}$ Although the decision of syndesmotic stability can be safely established with advanced radiological imaging studies such as ultrasound, computed tomography, and magnetic resonance imaging, ${ }^{[19,20]}$ very few of the respondents reported using them.

Almost half of the respondents stated that they used the hook test, external rotation stress test, and fluoroscopy together during the operation. The combined use of the hook test and other intraoperative methods was similar to the findings of previous studies. ${ }^{[8-12,16]}$ However, these results showed that Turkish orthopedic surgeons do not rely on the hook test alone as much as surgeons in the Netherlands. ${ }^{[9]}$ Another interesting finding from the current survey was that $15.6 \%$ of the participants stated that they had already decided before surgery whether or not they would perform syndesmotic fixation. These surgeons might be those who decide on the management plan according to the injury mechanism.

The majority of the participants $(92.8 \%)$ stated that they use metallic screws for syndesmotic injuries while $6 \%$ used SFD. The predominance of metallic screw use was consistent with previous studies (Table IV). However, SFD has been shown to provide adequate fixation in cadaveric and clinical studies, and there are also publications indicating better functional results than screws. ${ }^{[21]}$ The major disadvantage of using SFD is its cost and low availability compared with screws and is probably the reason for its limited use in this survey. Although the cost of SFD is higher than screws, when secondary procedures for device removal are considered, the cost for dynamic fixation has been found to be lower. ${ }^{[22]}$

Although $3.5 \mathrm{~mm}$ screws are more frequently broken than $4.5 \mathrm{~mm}$ screws, both screw sizes provide sufficient stability, while the size of the screw is still debatable ${ }^{[8]}$ In the current study, $3.5 \mathrm{~mm}$ screws were the most preferred size, although this rate was a little lower than that reported in the study by Schepers et al. ${ }^{[9]}$ Consistent with previous survey studies, Turkish orthopedic surgeons still prefer $3.5 \mathrm{~mm}$ screws over $4.5 \mathrm{~mm}$ screws (Table IV).

Biomechanically and clinically, there is no significant difference between three- and four-cortex fixations. The advantage of four-cortex screws seems to be that they are easier to remove in case of breakage while three-cortex screws have the advantage of allowing some physiological movement. ${ }^{[23]}$ In this study, $67 \%$ of the participants stated that they preferred three-cortex fixation while $32 \%$ preferred four-cortex fixation. This rate is consistent with previous survey studies except for the findings of Bava et al. ${ }^{[8]}$ The current study also showed that the choice of the 


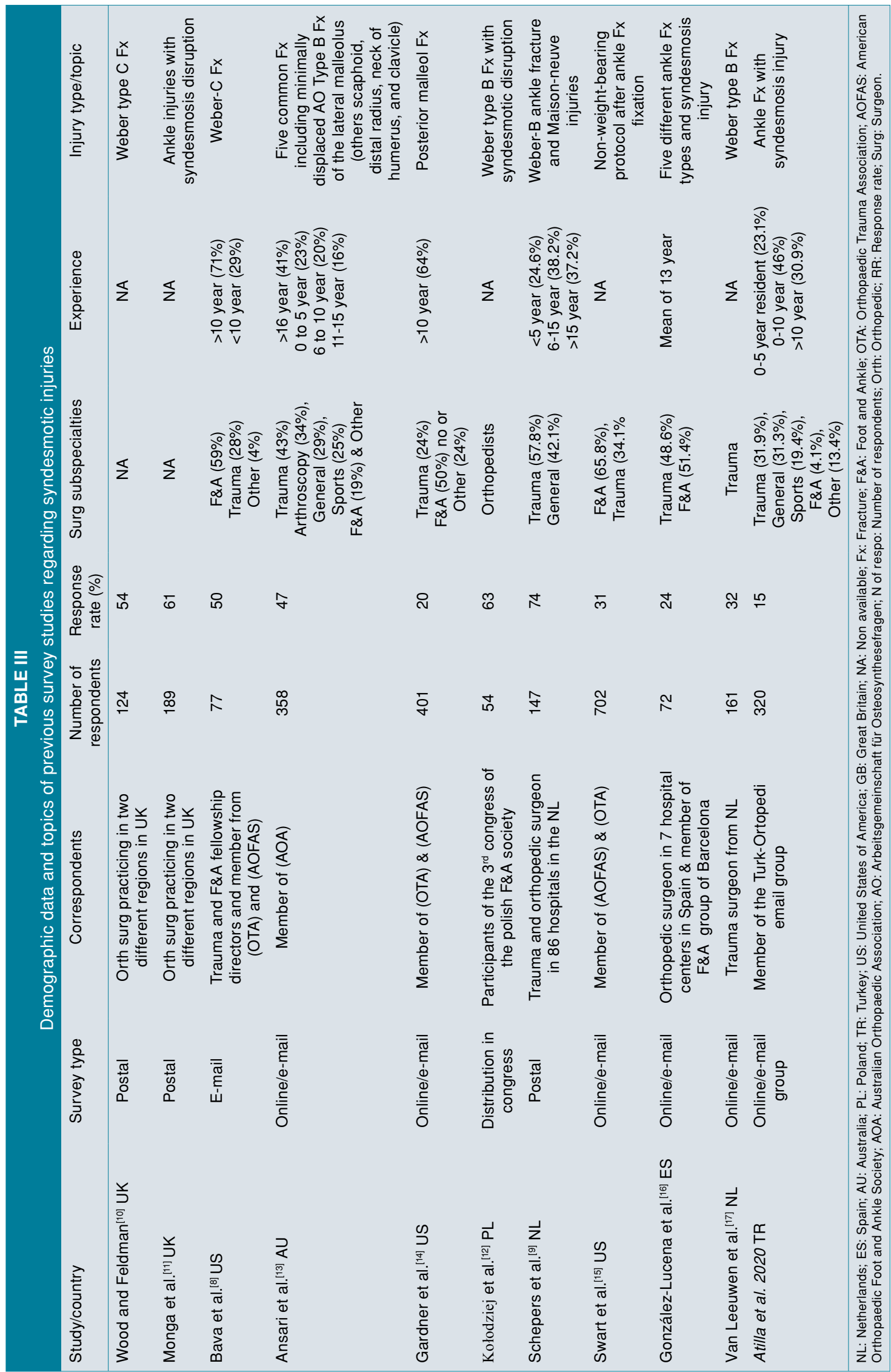




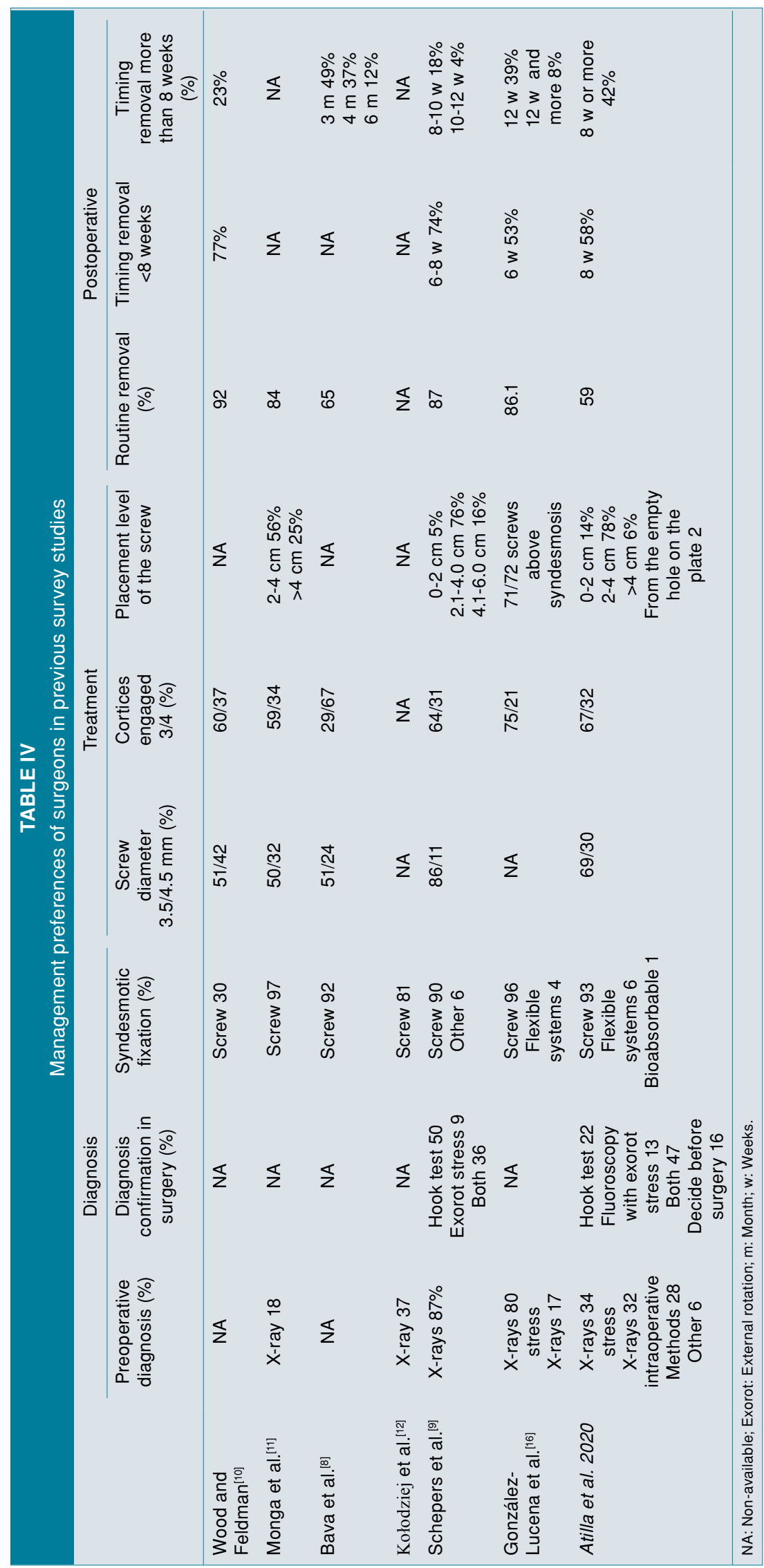


number of cortices to be fixed does not change with surgical experience or subspecialty.

The position of the screw and the position of the ankle during screw insertion are also controversial. The majority of participants in the current study preferred 2 to $4 \mathrm{~cm}$ proximal to the tibial plafond. Although the debate about the ideal location of the screw continues, 2 to $4 \mathrm{~cm}$ proximal to the joint seems to be the most appropriate site in the literature. ${ }^{[24]}$ Olerud ${ }^{[25]}$ stated that over-compression of syndesmosis would limit neutral range of motion, and this statement has led surgeons to fix the syndesmosis when the ankle is in maximum dorsiflexion. However, in later cadaver studies, it was shown that ankle position during fixation did not affect motion. ${ }^{[26]}$ Orthopedic surgeons are still confused between the previous and relatively new evidences.

Postoperative malreduction is common in such injuries and the reduction of syndesmosis is one of the most important indicators of good functional outcomes. ${ }^{[27]}$ Reduction of syndesmosis with the aid of a clamp has been previously reported to be a risk factor for postoperative malreduction. ${ }^{[28]}$ Instead of a wide clamp, reduction of syndesmosis by using hands and temporary Kirschner wire fixation reduces the malreduction rate. ${ }^{[28]}$ In the current study, reduction with a wide clamp was preferred at the rate of $43.4 \%$, and the rate of manual reduction was $46.3 \%$, which was higher than the findings of the study by Schepers et al. ${ }^{[9]}$ The rate of participants using methods other than these two responses was similar at $10.3 \%$. It seems that methods that are risky for syndesmotic malreduction are still commonly used.

The currently available literature does not support routine elective removal of syndesmotic screws. ${ }^{[29]}$ The removal of syndesmotic screws is advisable mainly in cases of patient complaints related to the other implanted perimalleolar hardware or malreduction of the syndesmosis after at least eight weeks postoperatively. ${ }^{[30]}$ In the current study, 58.8\% of the respondents reported routine removal of the syndesmotic screw. This is the lowest rate in the survey literature, and over the years, this is one of the most dramatically changed surgeon preferences in ankle fracture management surveys. However, 58\% of the respondents in the current study reported that if they remove the screw, it would be within eight weeks. Although this rate is high, Schepers et al. ${ }^{[9]}$ reported a higher rate of 73.9\% in 2012 (Table IV).

Surgeons with 10 years and less experience used intraoperative methods more than surgeons with
20 years or more experience. Although it has been known for many years that direct radiographs alone may be insufficient for the diagnosis of this injury, even experienced surgeons reported to establish decision by plain radiographs. ${ }^{[20]}$ González-Lucena et al. ${ }^{[16]}$ investigated whether foot surgeons have a different perspective for these injuries compared to general orthopedists and concluded that foot surgeons used more diagnostic tests, applied more diverse surgical techniques, and had lower revision rates. The majority of trauma, sports and foot surgeons allowed weight bearing without removing the trans-fixation screw. Orthopedic subbranches that frequently encounter ankle fractures in daily practice are more likely to risk the breakage of the screw when treating syndesmotic injuries by using a thinner screw and allowing weight bearing, and thus it can be said that other subbranches are more conservative in this regard.

There are several limitations of this study. The low response rate of this survey seems as a limitation, while the number of participants was one of the highest compared to similar surveys. Participation rate can be low if the source is a large general e-mail group rather than a directly postal or electronic mail touch. Nevertheless, by using the mail groups as data source, response rate can be low, while participation number increases. On the other hand, the survey was not questioned in respect of case samples; therefore, the medical status, age, and bone quality of patients could not be investigated. Lastly, there are no established fellowship education programs except hand and spine surgery in Turkey; consequently, the subspecialties of the surgeons can be accepted as the special interest or self-practice of the surgeons.

In conclusion, the preferences of surgeons still vary particularly in the diagnosis and rehabilitation of syndesmotic injuries. The dominant preference of using metallic screws is still persistent despite the reported better outcomes of SFDs. In treatment, surgeons have not reached an agreement upon the reduction technique or ankle position during screw placement. The rate of routine screw removal was the lowest compared to the similar surveys and this was the only changing attitude of surgeons in the last decade which was consistent with the recent scientific evidence. Since there are still many debatable issues and practices conflicting with the evidence, it would be beneficial to establish management guidelines for ankle fractures accompanying syndesmotic injuries. 


\section{Acknowledgements}

We thank Bülent Çelik, MD, Mehmet Faruk Çatma, MD, Atakan Gülsoy, MD, Muhammet Hayat, MD, and Barış Ekin Demir, MD, for their precious efforts and comments in the preparation of the questionnaire.

\section{Declaration of conflicting interests}

The authors declared no conflicts of interest with respect to the authorship and/or publication of this article.

\section{Funding}

The authors received no financial support for the research and/or authorship of this article.

\section{REFERENCES}

1. Tartaglione JP, Rosenbaum AJ, Abousayed M, DiPreta JA. Classifications in Brief: Lauge-Hansen Classification of Ankle Fractures. Clin Orthop Relat Res 2015;473:3323-8.

2. Harris J, Fallat L. Effects of isolated Weber B fibular fractures on the tibiotalar contact area. J Foot Ankle Surg 2004;43:3-9.

3. de-Las-Heras Romero J, Alvarez AML, Sanchez FM, Garcia AP, Porcel PAG, Sarabia RV, et al. Management of syndesmotic injuries of the ankle. EFORT Open Rev 2017;2:403-9.

4. Schnetzke M, Vetter SY, Beisemann N, Swartman B, Grützner PA, Franke J. Management of syndesmotic injuries: What is the evidence? World J Orthop 2016;7:71825.

5. Vopat ML, Vopat BG, Lubberts B, DiGiovanni CW. Current trends in the diagnosis and management of syndesmotic injury. Curr Rev Musculoskelet Med 2017;10:94-103.

6. Yaradılmış YU, Polat Y, Uslu MB, Ateş A, Demirkale İ, Altay M. The evaluation of radiological measurements used in diagnosis and treatment of syndesmosis injury: A regional study in Turkey. Jt Dis Relat Surg 2020;31:123-9.

7. van Dijk CN, Longo UG, Loppini M, Florio P, Maltese L, Ciuffreda $\mathrm{M}$, et al. Conservative and surgical management of acute isolated syndesmotic injuries: ESSKA-AFAS consensus and guidelines. Knee Surg Sports Traumatol Arthrosc 2016;24:1217-27.

8. Bava E, Charlton T, Thordarson D. Ankle fracture syndesmosis fixation and management: the current practice of orthopedic surgeons. Am J Orthop (Belle Mead NJ) 2010;39:242-6.

9. Schepers T, van Zuuren WJ, van den Bekerom MP, Vogels LM, van Lieshout EM. The management of acute distal tibio-fibular syndesmotic injuries: results of a nationwide survey. Injury 2012;43:1718-23.

10. Wood GCA, Feldman YA. Indications and use of the ankle syndesmosis screw: A multi-regional survey. Foot and Ankle Surgery 2004;10:65-69.

11. Monga P, Kumar A, Simons A, Panikker V. Management of distal tibio-fibular syndesmotic injuries: a snapshot of current practice. Acta Orthop Belg 2008;74:365-9.

12. Kołodziej $€$, Napiontek M. Methods of diagnosis and treatment of ankle fractures--the opinion of members and supporters of the Polish Foot and Ankle Society. Ortop Traumatol Rehabil 2011;13:387-97.

13. Ansari U, Adie S, Harris IA, Naylor JM. Practice variation in common fracture presentations: a survey of orthopaedic surgeons. Injury 2011;42:403-7.
14. Gardner MJ, Streubel PN, McCormick JJ, Klein SE, Johnson JE, Ricci WM. Surgeon practices regarding operative treatment of posterior malleolus fractures. Foot Ankle Int 2011;32:385-93.

15. Swart E, Bezhani H, Greisberg J, Vosseller JT. How long should patients be kept non-weight bearing after ankle fracture fixation? A survey of OTA and AOFAS members. Injury 2015;46:1127-30.

16. González-Lucena G, Pérez-Prieto D, López-Alcover A, Ginés-Cespedosa A. Ankle fracture controversies: Do the foot and ankle specialists have a different vision? Rev Esp Cir Ortop Traumatol 2018;62:27-34.

17. van Leeuwen CAT, Hoffman RPC, Donken CCMA, van der Plaat LW, Schepers T, Hoogendoorn JM. The diagnosis and treatment of isolated type B fibular fractures: Results of a nationwide survey. Injury 2019;50:579-89.

18. Atik OŞ. Is there something new and interesting in my article? Eklem Hastalik Cerrahisi 2019;30:69.

19. Chun DI, Cho JH, Min TH, Park SY, Kim KH, Kim JH, et al. Diagnostic Accuracy of Radiologic Methods for Ankle Syndesmosis Injury: A Systematic Review and MetaAnalysis. J Clin Med 2019;8:968.

20. Krähenbühl N, Weinberg MW, Davidson NP, Mills MK, Hintermann B, Saltzman CL, et al. Imaging in syndesmotic injury: a systematic literature review. Skeletal Radiol 2018;47:631-48.

21. Ræder BW, Figved W, Madsen JE, Frihagen F, Jacobsen SB, Andersen MR. Better outcome for suture button compared with single syndesmotic screw for syndesmosis injury: fiveyear results of a randomized controlled trial. Bone Joint J 2020;102-B:212-9.

22. Stiene A, Renner CE, Chen T, Liu J, Ebraheim NA. Distal tibiofibular syndesmosis dysfunction: A systematic literature review of dynamic versus static fixation over the last 10 years. J Foot Ankle Surg 2019;58:320-7.

23. Liu G, Chen L, Gong M, Xing F, Xiang Z. Clinical Evidence for Treatment of Distal Tibiofibular Syndesmosis Injury: A Systematic Review of Clinical Studies. J Foot Ankle Surg 2019;58:1245-50.

24. Hahn DM, Colton CL. Malleolar fractures. In: Ruedi T, Murphy W, editors. AO Principles of Fracture Management. New York: Thieme; 2001. p. 583-4.

25. Olerud C. The effect of the syndesmotic screw on the extension capacity of the ankle joint. Arch Orthop Trauma Surg 1985;104:299-302.

26. Pallis MP, Pressman DN, Heida K, Nicholson T, Ishikawa S. Effect of ankle position on tibiotalar motion with screw fixation of the distal tibiofibular syndesmosis in a fracture model. Foot Ankle Int 2018;39:746-50.

27. Sagi HC, Shah AR, Sanders RW. The functional consequence of syndesmotic joint malreduction at a minimum 2-year follow-up. J Orthop Trauma 2012;26:439-43.

28. Miller AN, Barei DP, Iaquinto JM, Ledoux WR, Beingessner DM. Iatrogenic syndesmosis malreduction via clamp and screw placement. J Orthop Trauma 2013;27:100-6.

29. Dingemans SA, Rammelt S, White TO, Goslings JC, Schepers T. Should syndesmotic screws be removed after surgical fixation of unstable ankle fractures? a systematic review. Bone Joint J 2016;98-B:1497-504.

30. Walley KC, Hofmann KJ, Velasco BT, Kwon JY. Removal of hardware after syndesmotic screw fixation: a systematic literature review. Foot Ankle Spec 2017;10:252-7. 